\title{
Individual attitudes towards migration: a reexamination of the evidence
}

\author{
Tobias Müller* and Silvio H. T. Tai ${ }^{\dagger}$
}

\begin{abstract}
Recent economic research has highlighted the importance of labor-market and welfare-state mechanisms in the explanation of individual attitudes towards immigration. By contrast, political scientists argue that attitudes are mostly determined by individual cultural values and beliefs. This paper takes a fresh look at this debate and contains the following contributions to the literature. First, we address the problem that unobserved cultural values and beliefs might be correlated with education, a potential source of bias in the estimations. Second, we compile a detailed database on the education levels of immigrants and natives and on the degree of fiscal redistribution in European countries. Third, our econometric estimates rely on a simple structural model, taking individual heterogeneity (with respect to education) explicitly into account. The structural model enables us to evaluate quantitatively the importance of the labor-market and welfare-state channels and of other individual factors (such as cultural values and beliefs). Our results show that the labor-market and welfare-state mechanisms play a significant role in explaining individual attitudes. However, the quantitative importance of these two mechanisms turns out to be rather limited compared to other individual factors.
\end{abstract}

\section{Resumo}

Estudos econômicos recentes tem evidenciado a importância de mecanismos como o mercado de trabalho e o estado de bem estar social na explicação das atitudes individuais em relação à imigração. Por outro lado, cientistas políticos argumentam que atitudes são majoritariamente determinadas por crenças e valores culturais individuais. Esse artigo traz uma nova visão nesse debate e contém as seguintes contribuições para a literatura. Primeiro, nós encaminhamos o problema que crenças e valores culturais não observados podem estar correlacionados com a educação, uma potencial fonte de viés nas estimações. Segundo, compilamos uma detalhada base de dados sobre os níveis de educação dos imigrantes e dos nativos e na redistribuição fiscal dos países europeus. Terceiro, as nossas estimativas econometricas são baseadas em um modelo estrutural simples, levando a heterogeneidade individual (em relação a educação) explicitamente em conta. O modelo estrutural nos possibilita avaliar quantitativamente a relativa importância do mercado de trabalho, do estado de bem estar social e de outros fatores individuais (como valores culturais e crenças). Nossos resultados mostram que os mecanismos de mercado de trabalho e o estado de bem estar social têm um papel importante na explicação das atitudes individuais. Entretanto, a importância quantitativa desses dois mecanismos são limitadas, comparada a dos outros fatores individuais.

*Department of economics, University of Geneva, Switzerland. Email: tobias.mueller@unige.ch

${ }^{\dagger}$ PPGE/PUCRS, Brazil. Email: silviotai@gmail.com 
JEL classification: F22, J61.

Keywords: Attitudes Toward Immigrants, Political Economy.

Área 6: Economia internacional 


\section{Introduction}

Although migration has been the neglected factor in globalization, its importance is rising fast. In Europe, many countries have seen important immigration flows in recent years and a large share of new jobs is occupied by immigrants. In 2003, $9 \%$ of the population in Austria was composed by immigrants, $8 \%$ in Belgium, 9\% in Germany, 40\% in Luxembourg, 7\% in Spain, 20\% in Switzerland and $5 \%$ in United Kingdom ${ }^{1}$. These trends can be expected to continue in the future, with growing migration pressure on the supply side and increasing needs for young workers in ageing societies. However, public opinion is not very favorable to further immigration in many European countries. For policy makers, it is crucial to understand the underlying causes of individual attitudes towards immigration. Are they mainly due to fears about labor market competition? Or are natives seeing immigration as a threat to the welfare state?

Recent economic research on attitudes toward migration applies individual-level data to distinguish labor market and welfare state channels. According to the first channel, the skill level of immigrants relative to that of natives influences the natives' receptiveness toward immigration (Scheve and Slaughter, 2001; Mayda, 2006; O'Rourke and Sinnott, 2006). Natives are more receptive to immigrants whose skills are complementary to their own (e.g., high-skill natives are in favor of lowskill immigration). More recently, Facchini and Mayda (2009) and Hanson et al. (2007) argue that individual attitudes depend also on the expected impact of immigration on the tax-benefit system in modern welfare states. In particular, low-skill immigrants might represent a burden especially for high-income natives in a redistributive system where low-income individuals receive (net) assistance from the state. By contrast, Hainmueller and Hiscox (2007) argue that attitudes toward immigration are mostly determined by individual values and beliefs, i.e. some individuals place greater value on ethnic diversity because of their cultural background. Dustman and Preston (2007) use a factor model to statistically compare the relative effect of the economic and non-economic channels. The existing literature does not succeed entirely in disentangling these different motives because the correlation between education and (unobserved) cultural values and beliefs has not been accounted for.

Our paper sheds new light on this debate and differs from past contributions in three respects. First, we exploit the fact that in the European Social Survey (2002), the same individual answers different questions on the desirability of immigration. Hence, we are able to take account of an individualspecific effect, capturing unobserved beliefs and values about immigration in general. Second, our econometric estimates rely on a simple structural model, taking individual heterogeneity (with respect to education) explicitly into account. Third, we use recent OECD data about the level of human capital of immigrants and natives in European countries, which allows us to measure the relative skill of immigrants with greater precision than in past work. In the following paragraphs, we discuss each aspect in turn.

We address the concern raised by Hainmueller and Hiscox (2007) that existing estimates of the relationship between education (or human capital) and attitudes towards immigration might be biased due to unobserved beliefs about immigration. First, we confirm their point that cultural values and beliefs seem to be linked more closely to immigration in general than to immigration from a specific region of origin. Second, we exploit the fact that each individual answers questions about the desirability of immigrants from different origins (rich or poor European countries, rich

\footnotetext{
${ }^{1}$ Source: OCDE (2007)
} 
or poor non-European countries). By estimating jointly attitudes towards different immigrant groups, we are able to control for unobserved individual factors that are linked to attitudes toward immigration in general.

Second, the use of a structural model with a continuous indicator of human capital enables us to identify the elasticity of substitution between (raw) labor and human capital. If this substitution elasticity is large (as we find), the impact of immigration on relative wages is small. This indicates that natives do not perceive the labor market channel as very important and tends to show that welfare state considerations are relatively more important. This result sheds new light on the relative importance of the labor market and welfare state channels, from an economic rather than statistical point of view.

Third, consistently with the theoretical model, we calculate relative skill ratios using a recent OECD (2008a) dataset. The relative skill ratios are defined for each destination country, and for different immigrant groups, based on a direct measure on the educational levels of immigrants. Therefore our relative skill ratio is much less subject to measurement error than the proxies (e.g. GDP per capita) used in previous contributions.

This paper is structured as follows. Section 2 presents the theoretical model and section 3 details the data. Section 4 reports on the findings and Section 5 presents the conclusion.

\section{Theoretical Model}

This section describes the simple economic model that will help us to determine how concerns about the labor market and and about the welfare state influence attitudes towards immigrants. We develop the model in two steps. First, the labor-market mechanism is analyzed using a model without taxation. Second, we consider the welfare-state channel by introducing a linear tax-benefit schedule in the model. Because of the assumption of a balanced government budget, the tax-benefit schedule has to adapt to the arrival of new immigrants. We will consider two polar cases: either the benefit changes (at constant marginal tax rates) or the marginal tax rate varies (at constant per capita benefits).

\subsection{The Labor Market Model}

Suppose there are $L^{N}$ national citizens and $L^{M}$ immigrants in the economy. Each individual $i$ supplies one unit of "raw" labor and $h_{i}$ units of human capital. Aggregate output is given by $Y=$ $F(H, L)$, where $L=L^{N}+L^{M}$ and $H=\sum_{i} h_{i}$ and $F$ is an aggregate production function exhibiting constant returns to scale. Per capita output can be written as $y \equiv Y / L=F(H / L, 1) \equiv f(h)$, where $h=H / L$ is the per capita human capital stock. ${ }^{2}$

\footnotetext{
${ }^{2}$ Physical capital can be added to the model without changing the qualitative conclusions if perfect international mobility of capital is assumed. To see this, define aggregate output as $Y=G(K, H, L)$, where $G$ is an aggregate production function with constant returns to scale. A factor-price constrained revenue function (Neary, 1985) can be defined as $\tilde{G}(r, H, L)=\max _{K}\{G(K, H, L)-r K\}$. With the world rental rate of capital $r^{*}$ given, the optimal stock of physical capital is defined implicitly by $\partial G / \partial K=r^{*}$ and $\tilde{G}$ has the same properties as an unconstrained revenue (or aggregate production) function, as shown by Neary (1985). Moreover, $\tilde{G}$ is linearly homogeneous with respect to $H$ and $L$. Therefore, if we assume that $r^{*}$ does not change with immigration, we can redefine $f$ as follows: $f(h)=\tilde{G}\left(r^{*}, H / L, 1\right)$.
} 
With perfectly competitive factor markets and profit maximization by the representative firm, prices and marginal products of production factors are equalized. Marginal products are given by $f^{\prime}(h)$ (human capital) and $f(h)-h f^{\prime}(h)$ (raw labor). Earnings of individual $i$ (holding $h_{i}$ units of human capital and 1 unit of raw labor) can therefore be written as

$$
y_{i}=f(h)-h f^{\prime}(h)+h_{i} f^{\prime}\left(h_{i}\right)=f(h)+\left(h_{i}-h\right) f^{\prime}(h) .
$$

We assume that individuals consider small changes in the average human capital $h$ of their country when they are asked about their immigration preferences. A small change in human capital has the following impact on an individual's income:

$$
d y_{i}=\left(h_{i}-h\right) f^{\prime \prime}(h) d h .
$$

The economy's average human capital stock $h$ increases (decreases) with immigration if immigrants are on average more (less) skilled than current residents. In the empirical implementation of the model, we consider different groups of immigrants, according to their region of origin. Denoting $h^{m}=H^{m} / L^{m}$ the average human capital of immigrants of group $m$, we have $d h=\left(h^{m}-h\right)\left(d L^{m} / L\right)$. Combining the latter expression with (refweq2) yields

$$
z_{i}^{m} \equiv \frac{d y_{i} / y}{d L^{m} / L}=\left(\frac{h_{i}}{h}-1\right)\left(1-\frac{h^{m}}{h}\right) \frac{1}{\sigma} \theta_{H} \theta_{L}
$$

where $\sigma$ is the elasticity of substitution between the inputs raw labor and human capital and $\theta_{H}$ and $\theta_{L}$ are the share of human capital and of raw labor in aggregate income 3

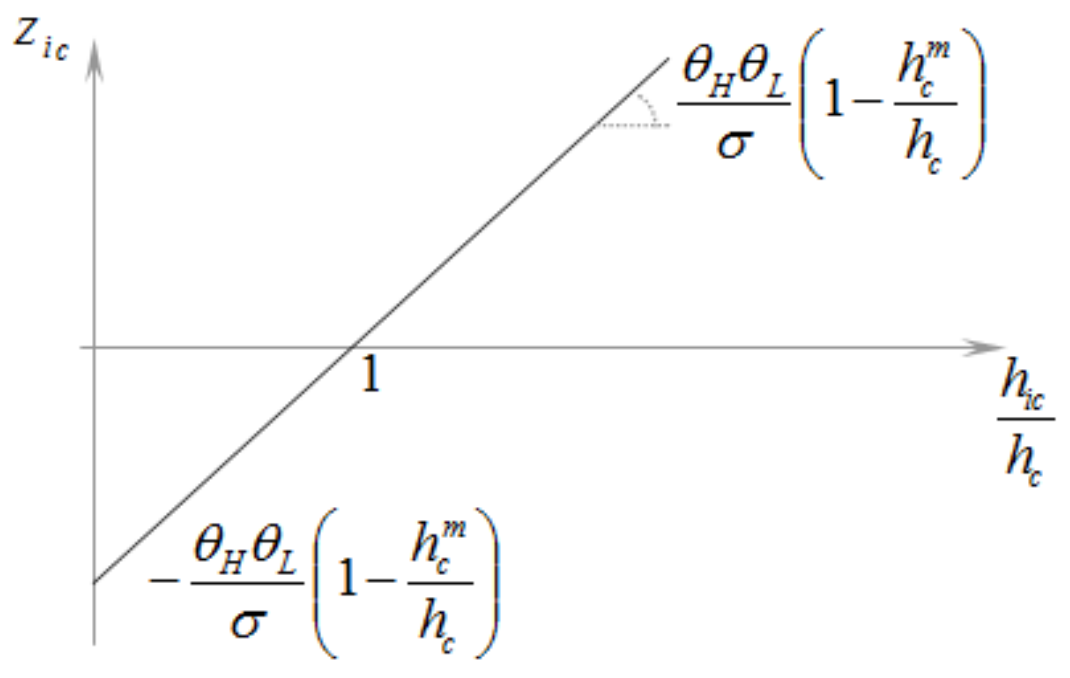

Figure 1: Labor Market Mechanism (Low-Skill Immigration, $h^{m}<h$ )

In view of the interpretation of our empirical results, it is useful to represent the relation between individual human capital and attitudes towards immigration as defined by equation (3). Figure 1

\footnotetext{
${ }^{3}$ Note that $\left[-h f^{\prime \prime}(h) f(h)\right] /\left[f^{\prime}(h)\left[f(h)-h f^{\prime}(h)\right)\right]$ equals the inverse of the elasticity of substitution $\sigma$.
} 
depicts the case where immigrants are on average less educated than the resident population $(1-$ $\left.h^{m} / h>0\right)$. Due to labor market competition, immigration reduces earnings of low-skilled natives and increases earnings of high-skilled natives.

When considering several countries, it is useful to introduce subscript $c$ for each destination country. In view of the estimation, we rewrite equation (3) as:

$$
z_{i c}^{m}=\frac{d y_{i c} / y_{c}}{d L_{c}^{m} / L_{c}}=\frac{h_{i c}}{h_{c}}\left(1-\frac{h_{c}^{m}}{h_{c}}\right) \frac{1}{\sigma} \theta_{H} \theta_{L}+\gamma_{c}^{m},
$$

where $\gamma_{c}^{m}=\left(\frac{h_{c}^{m}}{h_{c}}-1\right) \frac{1}{\sigma} \theta_{H} \theta_{L}$ collects all terms that are specific by country and by immigrant group.

\subsection{Adding the Welfare State}

The economic model can be extended to incorporate welfare state considerations by introducing income redistribution. This is the other major determinant of attitudes according to the recent economic literature (Facchini and Mayda, 2009; Hanson et al., 2007). Redistribution is accomplished using a linear tax-benefit schedule. A constant marginal tax rate $t$ is applied to each individual's income and each individual receives an identical benefit $b$. We require that the government's budget is balanced, which implies: $t f(h)=b$. Earnings of an individual $i$ can now be rewritten as: $y_{i}=(1-t)\left[f(h)+\left(h_{i}-h\right) f^{\prime}(h)\right]+b$.

With immigration, the tax-benefit schedule has to be adjusted in order to ensure a balanced budget of the government. Following Facchini and Mayda (2009), we focus on the two extreme cases where either the taxation level $t$ remains constant and the benefit $b$ adjusts, or the benefit remains constant and the marginal tax rate adjusts. The next paragraphs detail these two cases.

If we consider a constant marginal tax rate ( $b$ endogenous), a shock in tax revenues would lead to an adjustment in the level of the benefit. Therefore we have $t f^{\prime}(h) d h=d b$ and equation (3) becomes:

$$
z_{i}^{m}=\frac{d y_{i} / y}{d L^{m} / L}=\left(\frac{h_{i}}{h}-1\right)\left(1-\frac{h^{m}}{h}\right) \frac{1}{\sigma} \theta_{H} \theta_{L}(1-t)-\left(1-\frac{h^{m}}{h}\right) t \theta_{H} .
$$

How does the introduction of the welfare state change the relation between individual human capital and attitudes towards immigration? We consider the case of low-skill immigration where the benefit level adjusts to ensure a balanced government budget. Figure 2 compares the pure labor market model (dashed line) with the complete model which includes income redistribution. Two changes stand out. First, low-skill immigration represents a net cost for the tax-benefit system and entails therefore a decrease in the income of all natives. This is reflected by a downward shift in figure 2 . Second, taxation lowers the return to education and decreases therefore the slope in figure 2, It should be emphasized however, that the slope does not change sign, compared to the pure labor market model, if benefits adjust and the marginal tax rate is constant.

In view of the estimation, we can rewrite equation (5) as

$$
z_{i c}^{m}=\frac{h_{i c}}{h_{c}}\left(1-\frac{h_{c}^{m}}{h_{c}}\right) \frac{1}{\sigma} \theta_{H} \theta_{L}-t_{c} \frac{h_{i c}}{h_{c}}\left(1-\frac{h_{c}^{m}}{h_{c}}\right) \frac{1}{\sigma} \theta_{H} \theta_{L}+\omega_{c}^{m},
$$




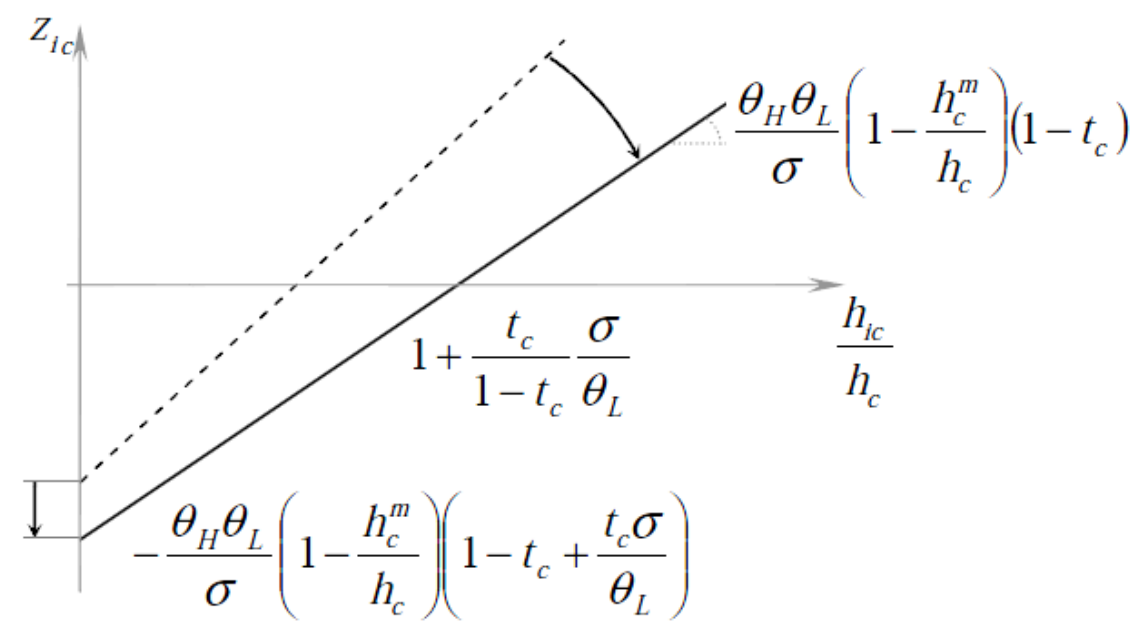

Figure 2: Welfare Mechanism - Benefit Adjustment (Low-Skill Immigration, $h^{m}<h$ )

where $\omega_{c}^{m}=\left(1-\frac{h_{c}^{m}}{h_{c}}\right)\left(\frac{t}{\sigma} \theta_{H} \theta_{L}-\frac{1}{\sigma} \theta_{H} \theta_{L}-t \theta_{H}\right)$ collects all terms that are specific by country and by immigrant group.

Turn now to the alternative case where the marginal tax rate $t$ adjusts to compensate a variation in government revenues. Considering the benefit $b$ constant, the marginal tax rate $t$ is endogenous, $t f^{\prime}(h) d h+f(h) d t=0$, and equation (3) becomes:

$$
z_{i}^{m}=\frac{d y_{i} / y}{d L^{m} / L}=\left(\frac{h_{i}}{h}-1\right)\left(1-\frac{h^{m}}{h}\right)\left(\frac{1}{\sigma} \theta_{H} \theta_{L}(1-t)-t \theta_{H}^{2}\right)-\left(1-\frac{h^{m}}{h}\right) t \theta_{H} .
$$

In the case of low-skill immigration, the marginal tax rate has to increase in order to ensure a balanced government budget. As a consequence, highly skilled natives have to bear a greater share of the welfare cost from immigration than unskilled natives. This adjustment is reflected by a large change in the slope in figure 3. As the analytical expression makes clear, the rotation is much larger than in the previous case and individual human capital and attitudes towards immigration may even become negatively related if the fiscal costs of low-skill immigration are higher than the complementarity advantages in the labor market. The latter outcome will be observed in countries with a large welfare state (i.e. a large initial $t$ ). As the benefit level is kept constant in this case, low-skill natives are better protected than in the benefit-adjustment case (the downward shift in figure 3 is less pronounced).

In view of the estimation, we can rewrite equation (7) as

$$
z_{i c}^{m}=\frac{h_{i c}}{h_{c}}\left(1-\frac{h_{c}^{m}}{h_{c}}\right) \frac{1}{\sigma} \theta_{H} \theta_{L}-t_{c} \frac{h_{i c}}{h_{c}}\left(1-\frac{h_{c}^{m}}{h_{c}}\right)\left(\theta_{H}^{2}+\frac{1}{\sigma} \theta_{H} \theta_{L}\right)+\kappa_{c}^{m},
$$

where $\kappa_{c}^{m}=\left(1-\frac{h_{c}^{m}}{h_{c}}\right)\left(\frac{t}{\sigma} \theta_{H} \theta_{L}-\frac{1}{\sigma} \theta_{H} \theta_{L}-t \theta_{H}+t \theta_{H}^{2}\right)$ collects all terms that are specific by country and by immigrant group. 


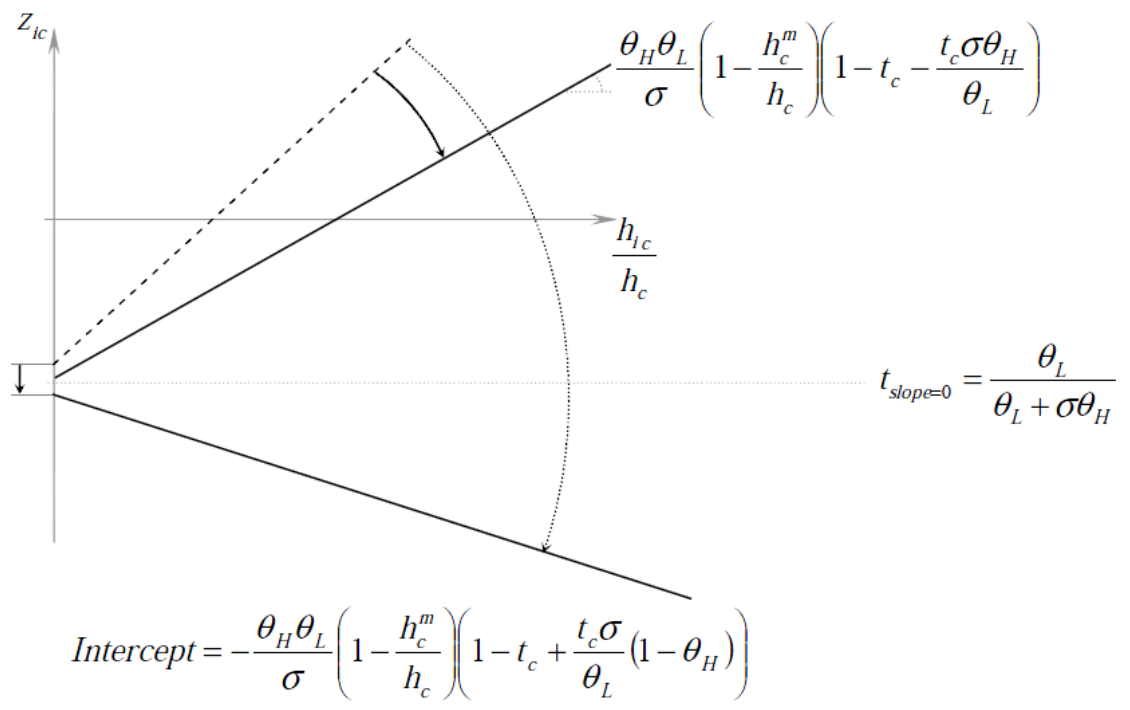

Figure 3: Welfare Mechanism - Tax Adjustment (Low-Skill Immigration, $h^{m}<h$ )

\subsection{Cultural Values and Beliefs}

In the economic model spelled out above, worries about labor market competition and the welfare state are the only determinants of natives' attitudes toward immigrants. In contrast, recent research in other disciplines (see Hainmueller and Hiscox, 2007) suggests noneconomic explanations for these attitudes. According to these authors, cultural or ideological factors would have a primary impact on natives' opinions, above any economic mechanism. Moreover, Hainmueller and Hiscox (2007) posit a correlation between openness to other cultures and the natives' education level, and relate low education levels and "xenophobic or racist predilections". In their view, education is not a proxy for human capital but has a direct link to general attitudes towards immigration. More educated individuals support more cultural diversity, regardless of the immigrants' skill level.

The correlation between education and openness towards other cultures is particularly a problem in the econometric analysis, since it implies a missing variable in equations (4) to (8). Clearly, the estimate equation incorporates not only a stochastic error $\epsilon_{i c}^{m}$, but also a missing "cultural" or "ideological" variable correlated with the individual level of education. This important issue is addressed in the empirical analysis.

\section{Data}

\subsection{Attitudes Towards Immigrants}

Data on attitudes are taken from the first round of the European Social Survey (ESS) which covers

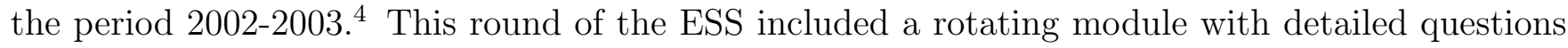
about attitudes to immigration, according to the location and the wealth of the immigrant's origin country. Using a scale from 1 (few) to 4 (many) $)^{5}$ a respondent living in country C answers different

\footnotetext{
${ }^{4}$ Table ?? in the appendix lists destination countries and their respective frequency in the survey. For more information, see http://www . europeansocialsurvey.org/

${ }^{5}$ Original questions use an inverted scale.
} 
versions of the question: "to what extent do you think country $\mathrm{C}$ should allow people from [region of origin] to come and live here?". The four regions of origin (and the corresponding answers) are the following:

rich_eur: allow many/few immigrants from richer countries in Europe poor_eur: allow many/few immigrants from poorer countries in Europe rich_out: allow many/few immigrants from richer countries outside Europe poor_out: allow many/few immigrants from poorer countries outside Europe

Compared to previous studies, the analysis of this data base presents the advantage of assessing attitudes toward immigrants, taking into account individual variability. In other words, not only the general opinion concerning migration is available, but each respondent can express different attitudes according to the origin of immigrants. Figure 4 indicates the average opinions expressed in each destination country. In each destination country, these attitudes exhibit little variability with respect to the origin of the immigrants. Broadly speaking, respondents are either receptive or hostile to immigration regardless of the immigrants' origin (from Europe or not, from a rich country or not). At first glance this observation gives some support to the arguments of Hainmueller and Hiscox (2007) who point out that individuals base their attitudes more on cultural values and beliefs than on economic factors. While the economic factors would depend on the characteristics of immigrants relative to the characteristics of natives, the cultural factors and beliefs would depend solely on the education level of the native. Moreover, as these beliefs relate to immigration in general, an individual tends to answer in the same way the four questions above, disregarding the origin of the immigrant.

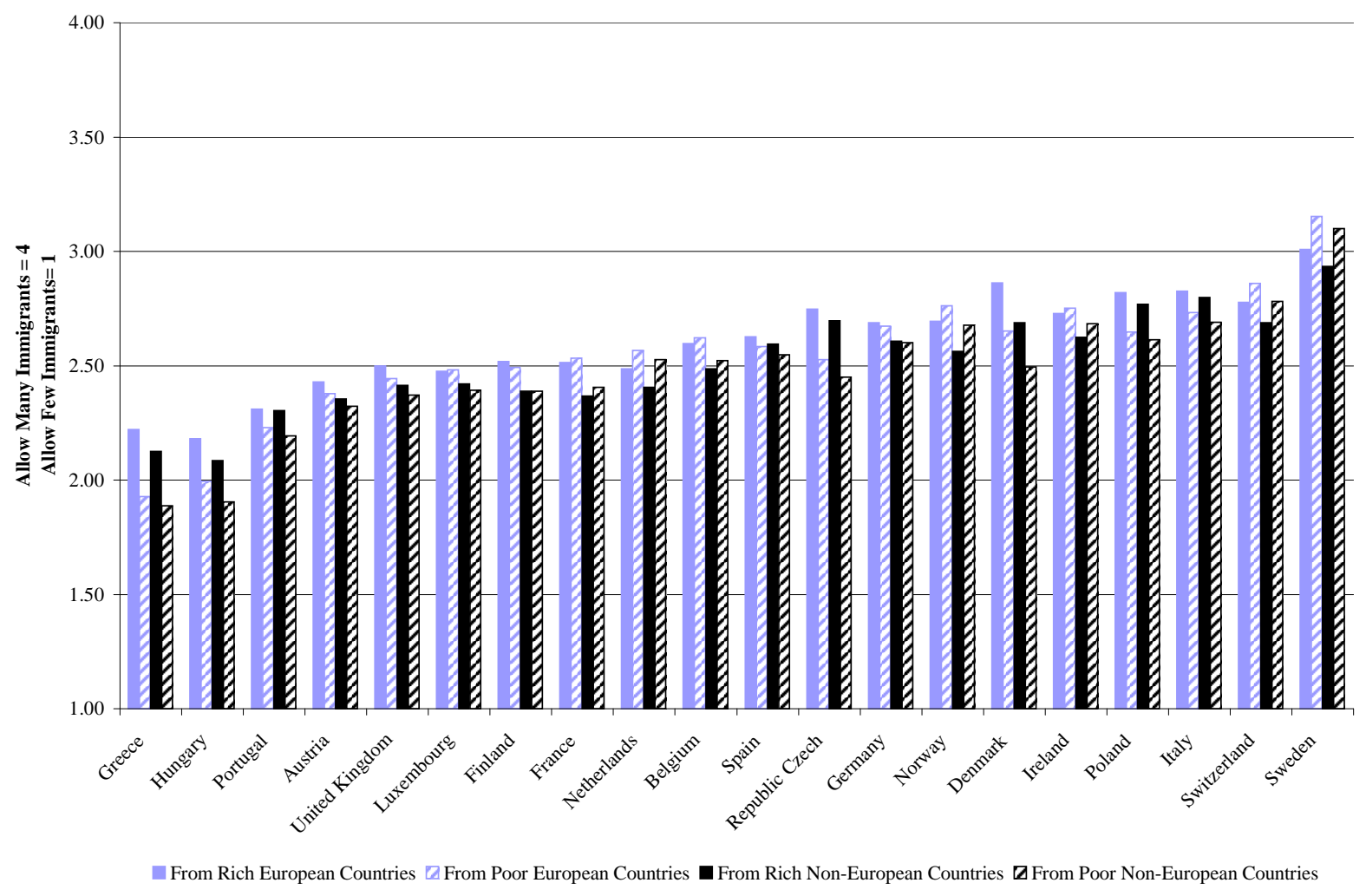

Figure 4: Average Attitudes by Destination Country 
In the context of our analysis, it is important to check whether cultural values and beliefs are related to attitudes to immigration in general or if they vary with the origin of immigrants. Thus, we decompose the answer to each of the four questions into a general component (common to all questions) and a component which is specific to the origin of the immigrants (rich or poor countries). The general component of attitudes is measured as the average attitude toward immigrants regardless whether they come from poor or rich countries. The specific attitude is the deviation of the attitudes regarding each category of immigrant (poor or rich) from the average. If the argument of Hainmueller and Hiscox (2007) stands, one would expect that individual cultural beliefs are more correlated with the general component than with specific attitudes. The ESS survey provides some questions with a cultural content (e.g. "Is the country's cultural life undermined or enriched by immigrants?"). Table 1 presents the decomposition of the covariances between attitudes and some "cultural content" questions. One can see that these "cultural opinions" are mostly correlated with the general component of attitudes. Specific attitudes to immigrants from poor countries (or from rich countries) are only weakly correlated to these individual opinions. Taking the second question as an example, this decomposition is formalized by:

Cov $($ ind_opinion, poor_eur $)=\operatorname{Cov}($ ind_opinion, avg_eur $)+C o v($ ind_opinion, $\Delta$ poor_eur $)$ where avg_eur $=($ poor_eur + rich_eur $) / 2$ and $\Delta$ poor_eur $=$ poor_eur - avg_eur

More than $90 \%$ of the covariance between the opinion that "immigrants undermine a country's culture" and attitudes toward immigrants from poor countries can be attributed to the general component of attitudes. This result, and the other decompositions in table 1, seem to confirm the existence of individual values that are related to immigration in general. Our econometric analysis below take this into account.

Table 1: Decomposition of the Covariances: Some Native's Individual Characteristics

\begin{tabular}{|c|c|c|c|c|c|c|c|c|}
\hline \multirow{2}{*}{$\begin{array}{l}\text { Individual Native's Opinions } \\
\text { Immigrants: }\end{array}$} & \multicolumn{4}{|c|}{ Europe } & \multicolumn{4}{|c|}{ RoW } \\
\hline & $\begin{array}{l}\text { allow p } \\
\text { average }\end{array}$ & $\begin{array}{l}\text { or immig? } \\
\text { deviation }\end{array}$ & $\begin{array}{l}\text { allow ri } \\
\text { average }\end{array}$ & $\begin{array}{l}\text { immig.? } \\
\text { deviation }\end{array}$ & $\begin{array}{l}\text { allow p } \\
\text { average }\end{array}$ & $\begin{array}{l}\text { or immig? } \\
\text { deviation }\end{array}$ & $\begin{array}{l}\text { allow ri } \\
\text { average }\end{array}$ & $\begin{array}{l}\text { h immig? } \\
\text { deviation }\end{array}$ \\
\hline 1. contribute to taxes? & $89.2 \%$ & $10.8 \%$ & $113.8 \%$ & $-13.8 \%$ & $87.4 \%$ & $12.6 \%$ & $116.9 \%$ & $-16.9 \%$ \\
\hline 2. bring down wages? & $89.9 \%$ & $10.1 \%$ & $112.7 \%$ & $-12.7 \%$ & $89.9 \%$ & $10.1 \%$ & $112.7 \%$ & $-12.7 \%$ \\
\hline 3. should belong to the majority's race? & $96.4 \%$ & $3.6 \%$ & $103.9 \%$ & $-3.9 \%$ & $96.8 \%$ & $3.2 \%$ & $103.4 \%$ & $-3.4 \%$ \\
\hline 4. undermine country's culture? & $90.7 \%$ & $9.3 \%$ & $111.5 \%$ & $-11.5 \%$ & $90.1 \%$ & $9.9 \%$ & $112.4 \%$ & $-12.4 \%$ \\
\hline 5. get crime problem worse? & $89.2 \%$ & $10.8 \%$ & $113.8 \%$ & $-13.8 \%$ & $87.2 \%$ & $12.8 \%$ & $117.2 \%$ & $-17.2 \%$ \\
\hline 6. should be christian? & $88.4 \%$ & $11.6 \%$ & $115.1 \%$ & $-15.1 \%$ & $86.6 \%$ & $13.4 \%$ & $118.3 \%$ & $-18.3 \%$ \\
\hline 7. should be white? & $86.9 \%$ & $13.1 \%$ & $117.7 \%$ & $-17.7 \%$ & $84.6 \%$ & $15.4 \%$ & $122.2 \%$ & $-22.2 \%$ \\
\hline
\end{tabular}

\subsection{Measure of Human Capital}

In our model, two indicators play a crucial role: the ratio between a native's human capital and his country's average human capital $\left(h_{i c} / h_{c}\right)$, and the ratio between immigrants' human capital and the host country's average human capital $\left(h_{c}^{m} / h_{c}\right)$. To ensure consistent measurement, we will use a single data source for each of the two ratios (ESS for the former, OECD (2008b) for the latter) and define a measure of human capital that is consistent with our theoretical framework. Our measure of human capital is inspired by the empirical growth literature (Klenow and Rodriguez-Clare, 2005) 
where human capital per capita is defined as a Mincerian function of schooling: $e^{\rho s}$, where $s$ denotes years of schooling attainment. $[6$

Our model differs from the aggregate production function used in these growth models because we distinguish "raw" labor from human capital. Therefore, our measure of human capital should exclude the return to raw labor. In our model, individual income is given by $y_{i}=F_{L}+F_{H} h_{i}$ whereas the Mincer model states that $y_{i}=c e^{\rho s_{i}}$, where $\rho$ is the return to schooling $\left(s_{i}\right)$. To ensure consistency between the two, we define individual human capital as $h_{i}=\left(c e^{\rho s_{i}}-F_{L}^{0}\right) /\left(F_{H}^{0}\right)$ where superscript 0 denotes values at the initial equilibrium. Defining the marginal productivity of "raw labor" as $F_{L}^{0}=c e^{\rho s_{\min }}$ (and assuming that $F_{H}^{0}=F_{L}^{0}$ by choice of units) yields the following measure of individual human capital:

$$
h_{i}=e^{\rho\left(s_{i}-s_{\min }\right)}-1
$$

where $s_{\text {min }}$ denotes "minimum" years of schooling which correspond to our definition of raw labor. The return to schooling $\rho$ is set to $8.5 \%$, following Klenow and Rodriguez-Clare (2005) who rely on the returns estimated by Psacharopoulos and Patrinos (2004) for a large set of countries.

Now turn to the measure of the ratio $h_{i c} / h_{c}$. The ESS survey presents two main variables concerning native individual education. The variable edulvl provides the level of education according to the following categories: not completed primary education, primary or first stage of basic, lower secondary or second stage of basic, upper secondary, post secondary non-tertiary, first stage of tertiary, second stage of tertiary. The variable eduyrs provides the years of education for each individual. We want to translate the different education levels into years of schooling attainment, regardless of how many years it takes an individual to reach a given education level. Therefore our measure of the individual years of schooling $s_{i}$ of natives is defined as the median (in the entire sample) of eduyrs within each education level $(e d u l v l)$. Individual human capital is then calculated using (9) and $h_{c}$ is obtained by averaging over the natives of each country $c$. As the lowest education level in our sample corresponds to 4 years of schooling, we set $s_{\min }$ to 4 .

Data on immigrants' education level are obtained from OECD (2008)..$^{7}$ The level of education is provided for natives and immigrants by categories following the International Standard Classification of Education (ISCED) 1997.8 In the data, four categories gather the six levels of ISCED classification, namely: primary level (ISCED 0/1/2), secondary level (ISCED 3/4), tertiary level 1 (ISCED 5A/5B) and tertiary level 2 (ISCED 6). Following the ISCED definitions and according to educational system the European countries, we attributed a certain number of years to each education category $!^{9}$

To define the four group of immigrants that appear in the survey questions, we have to distinguish "poorer countries" from "richer countries" in Europe and in the Rest of the world. In both regions,

\footnotetext{
${ }^{6} \mathrm{~A}$ more complete version of the Mincer model would include individuals' work experience in addition to schooling. We do not include years of experience in our measure of human capital. First, experience could only be measured as potential experience using data on age (e.g., experience=age-schooling years-6), involving important measurement errors especially for women. Second, the literature agrees on the fact that substitution across experience groups is much easier than substitution between education levels. Our measure of human capital should reflect primarily differences between education levels since in our model, human capital and raw labor are imperfect substitutes.

${ }^{7}$ Docquier et al. (2009) provide another, widely used database on stocks of immigrants and natives by education level. As the disaggregation of education levels is finer in OECD (2008), we chose to use the latter.

${ }^{8}$ Available at http://www.unesco.org/education/information/nfsunesco/doc/isced_1997.htm

${ }^{9}$ We attribute 8 years to the primary level, 12 years to the secondary level, 15 years to the tertiary level 1 and 17 years to the tertiary level 2 .
} 
we classify countries with a GDP per capita higher than $\$ 10,000$ as "rich countries" and all others as "poor countries" (source: World Development Indicators for the year 2003). This classification yields country groups that seem to correspond to the general perception of rich and poor countries. For example, Hungary and Gabon are considered to be poor countries (for a complete listing, see figures ?? and ?? in appendix I). Our classification of rich countries is also very close to the category of "high income" countries established by the World Bank.10

\subsection{Other Explanatory Variables}

In our model, the welfare state is represented by a simple linear tax-benefit system. To measure the degree of redistribution in all destination countries, we rely on indicators published by the OECD in the "Taxing Wages" series. For all 20 destination countries, we estimate marginal tax rates that are representative of the real income tax paid by wage earners. The OECD provides average and marginal tax rates at four different points of the wage distribution for adult, full-time workers in manufacturing sectors: at $67 \%, 100 \%, 133 \%$ and $167 \%$ of average earnings. ${ }^{11}$

We use two simple methods to estimate a unique marginal tax rate for each country, based on the tax schedule for single wage earners. First, we calculate a simple average of marginal tax rates at the four points of the income distribution. Second, we adjust a linear tax-benefit schedule to the average tax rates at the four points of the wage distribution 12 Reassuringly, the two simple methods yield very similar results. The only noticeable differences between the two methods appear when there is a large jump in marginal tax rates at one point of the income distribution (Greece, United Kingdom). In the following section, we report estimation results using the tax data obtained from the first method but none of our results change significantly if we use the alternative data set.

\section{Results}

As our discussion in section 3.1 made clear, the descriptive evidence points to the existence of cultural values and beliefs that influence individual attitudes towards immigration in general. In the estimation of the model, we will therefore focus on the question whether economic factors matter in the relationship between education (or human capital) and attitudes towards immigration even if unobserved beliefs about immigration in general are taken into account in the estimation procedure. Following the discussion in the recent literature, we explore first the labor market channel which was put forward by Scheve and Slaughter (2001), Mayda (2006) and O'Rourke and Sinnott (2006) and put into question by Hainmueller and Hiscox (2007). It turns out that fears about labor market competition, when taken on their own, do not provide a consistent explanation of attitudes towards immigration in Europe. In a second step, we add welfare state considerations (as explored by

\footnotetext{
${ }^{10}$ The World Bank divides countries into four groups according to their GNI per capita. For the year 2003 the categories were defined as follows: low income, $\$ 735$ or less; lower middle income, $\$ 736$ - $\$ 2,935$; upper middle income, $\$ 2,936$ - $\$ 9,075$; and high income, $\$ 9,076$ or more.

${ }^{11}$ Prior to 2004-2005, the OECD calculated average earnings only for manual workers in manufacturing. We use the "new definition" which is an average for both manual and non-manual workers in manufacturing.

${ }^{12}$ Denote the tax paid by the individual by $T=t Y-b$, where $Y$ is the individual's income. The average tax rate is $T / Y=t-b(1 / Y)$. Therefore, we regress the average tax rate on the inverse of income. The constant term of the regression is the estimated unique marginal tax rate.
} 
Hanson et al., 2007, and Facchini and Mayda, 2009) and find consistent results. We report below only results for the second step. Results for the first step are provided under request.

\subsection{Taking the Welfare State into Account}

The welfare state changes the relation between human capital and attitudes towards immigration. The sign of this relationship can even be reversed (compared to the labor market model) if there is a high level of income redistribution and if the marginal tax rate is adjusted in order to keep social benefits at the initial level. More specifically, a high-skilled native does not compete with a low-skilled immigrant in the labor market, but the arrival of the latter can deteriorate the former's fiscal situation.

In the theoretical framework, we allowed for two possible adjustments of the government budget: either the benefit level or the marginal tax rate adjusts to the new situation created by immigration. In view of the econometric estimation, the theoretical equations (6) and (8) corresponding to these two cases can be summarized as follows

$$
\tilde{z}_{i c}^{m}=\lambda_{0}+\lambda_{1} A_{i c}+\lambda_{2} A_{i c} R_{c}^{m}+\lambda_{3} t_{c} A_{i c} R_{c}^{m}+v_{c}^{m}+\mu_{i c}+\epsilon_{i c}^{m}
$$

where $v_{c}^{m}$ is a country/immigrant group fixed effect and $\mu_{i c}$ is the unobserved individual effect capturing general attitudes to immigration.

As in the previous specification with labor market, the procedure developed by Chamberlain (1984) is applied. The random-effects logit model is regressed considering individual omitted factors correlated with regressors as follows: $\mu_{i c}=\nu_{1} A_{i c} R_{c}^{\text {poor }}+\nu_{2} A_{i c} R_{c}^{\text {rich }}+\xi_{1} t_{c} A_{i c} R_{c}^{\text {poor }}+\xi_{2} t_{c} A_{i c} R_{c}^{\text {rich }}+\eta_{i c}$. In this case, our estimated equation becomes:

$\tilde{z}_{i c}^{m}=\lambda_{0}+\lambda_{1} A_{i c}+\lambda_{2} A_{i c} R_{c}^{m}+\lambda_{3} t_{c} A_{i c} R_{c}^{m}+\nu_{1} A_{i c} R_{c}^{p o o r}+\nu_{2} A_{i c} R_{c}^{r i c h}+\xi_{1} t_{c} A_{i c} R_{c}^{\text {poor }}+\xi_{2} t_{c} A_{i c} R_{c}^{r i c h}+\delta^{\prime} X_{i c}+v_{c}^{m}+\epsilon_{i c}^{m}$

The two versions of the theoretical model can be distinguished as follows. If the benefit level $b$ is endogenous, the theoretical model predicts that

$$
\lambda_{1}=0, \quad \lambda_{2}=-\lambda_{3}=\theta_{H} \theta_{L} / \sigma .
$$

Both restrictions can be tested.

By contrast, if the marginal tax rate $t$ is endogenous, the theoretical model predicts that

$$
\lambda_{1}=0, \quad \lambda_{2}=\theta_{H} \theta_{L} / \sigma, \quad \lambda_{3}=-\left(\theta_{H}^{2}+\theta_{H} \theta_{L} / \sigma\right)
$$

To choose the relevant version of the model, we proceed as follows. First, we test the restriction $\lambda_{2}+\lambda_{3}=0$. If this restriction cannot be rejected, we conclude that the benefit level $b$ adjusts endogenously. Note that, similarly to the labor market model, $\sigma$ cannot be identified in this case. If the restriction $\lambda_{2}+\lambda_{3}=0$ is rejected and if $\lambda_{2}$ and $\lambda_{3}$ have the signs predicted by the theoretical model, we conclude that the marginal tax rate $t$ adjusts endogenously. In this case, the elasticity 
of substitution $\sigma$ between raw labor and human capital can be identified assuming that $\theta_{H}$ and $\theta_{L}$ are known 13

$$
\sigma=-\frac{\theta_{L}}{\theta_{H}}\left(\frac{\lambda_{3}}{\lambda_{2}}+1\right)
$$

Table 2 presents estimation results for this model, using the three different econometric approaches discussed above. Unlike the labor market model, the random-effects and fixed-effects logit models (regressions (5) to (10)) give consistent results when welfare state considerations are taken into account. This important result reverses our previous conclusions and seems to indicate that the correlation between cultural values and education does not matter in the estimation if the model accounts for taxation and redistribution. We can therefore conclude that the labor market model gives an incomplete description of attitudes towards immigration.

What do these results tell us about the way the government budget adjusts to immigration? The restriction $\lambda_{2}+\lambda_{3}=0$ is rejected in specifications (5) to (10) at the 1 percent level. On the other hand, $\lambda_{2}$ and $\lambda_{3}$ have the signs predicted by the second version of the model where $t$ adjusts endogenously. Hence, the impact of immigration on government revenues is predominantly absorbed by a rise in marginal tax rates instead of a reduction in the benefit level.

The ordered probit estimates in regressions (1),(3) and (4) do not yield significant results for the variables that are relevant from an economic point of view. A first explanation that comes to mind is that these estimates are biased since they do not account for the unobserved beliefs and values towards immigration.

\footnotetext{
${ }^{13}$ Using the entire sample, we calculate the average share of raw labor $\left(\theta_{L}=1-\theta_{H}\right)$ as follows: $\sum_{i} \exp \left[\rho\left(s_{i}-\right.\right.$ $\left.\left.s_{\text {min }}\right)\right]=0.5421$, using $\rho=8.5 \%$.
} 


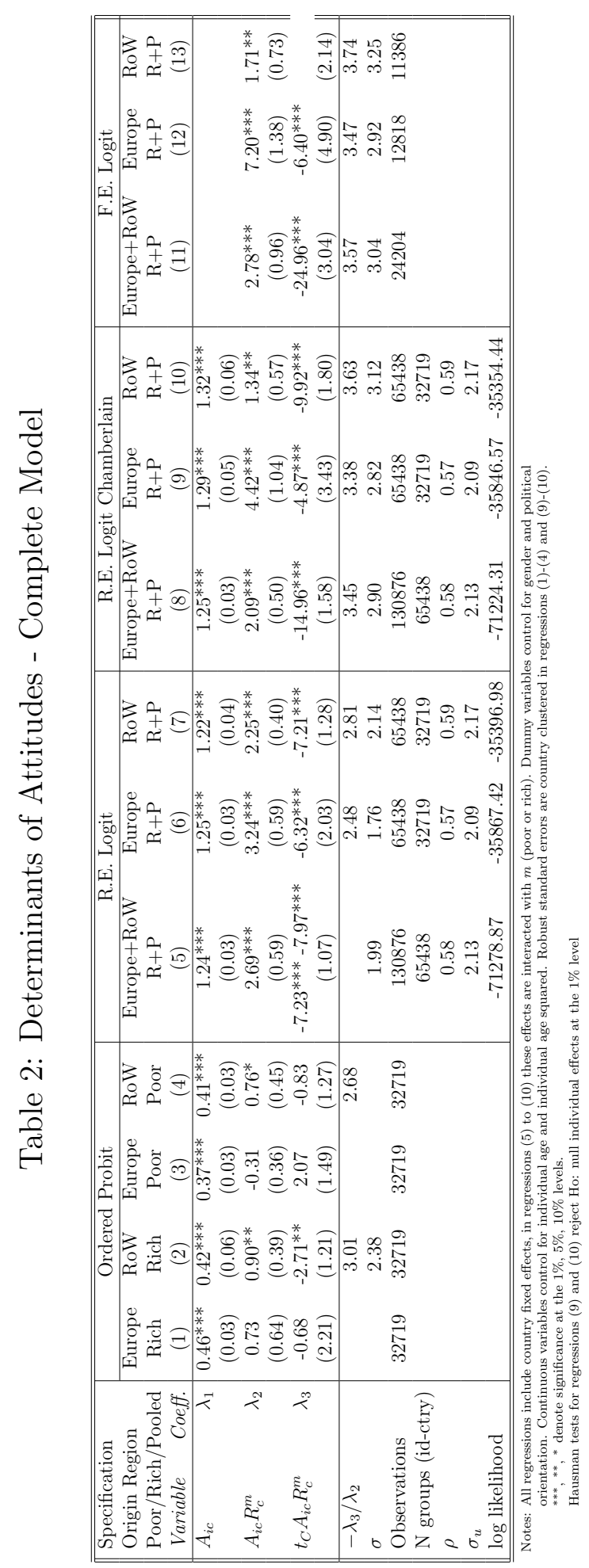


Finally, a remarkable result is that the ratio $-\lambda_{3} / \lambda_{2}$ does not vary much across the different regressions (between 2.48 and 3.74). This implies that our model yields a rather robust estimate of the elasticity of substitution between raw labor and human capital. For our preferred estimation methods (random-effects-Chamberlain logit and fixed effects logit), the values for $\sigma$ vary between 2.82 and 3.25. In the context of our theoretical framework, these rather high elasticities indicate that natives perceive a small impact of immigration on relative wages, a result which seems consistent with the empirical literature on the labor market consequences of immigration.

\subsection{Are Individual Values and Beliefs Relevant?}

The econometric analysis developed so far allows us to identify the economic channels via which attitudes are determined. However, it does not evaluate the importance of individual values and beliefs. This section clarifies the role of these values, comparing them to the economic mechanisms. This is possible by simulating the econometric model with different configuration of parameters. Predicted values of the model give us the "total" attitudes towards immigration of the natives. The contribution of the "welfare state" mechanism to attitudes can be calculated as follows. Setting marginal tax rates equals to zero, we recalculate predicted attitudes of the model. This provides a measure of attitudes in the absence of a welfare state, including only the two mechanisms of "labor market competition" and "individual values and beliefs" "14 The difference between "total attitudes" and the latter predicted attitudes represents the contribution of the welfare mechanism. Analogously, we obtain the predicted values of attitudes determined by the labor market mechanism. The difference between the "total" prediction and the prediction determined by the economic factors is attributed to the individual beliefs.

\footnotetext{
${ }^{14}$ In practice, it corresponds to impose $\lambda_{3}$ equals to zero and to correct the fixed effects before the simulation, a detailed description of this procedure is available in Appendix III.
} 

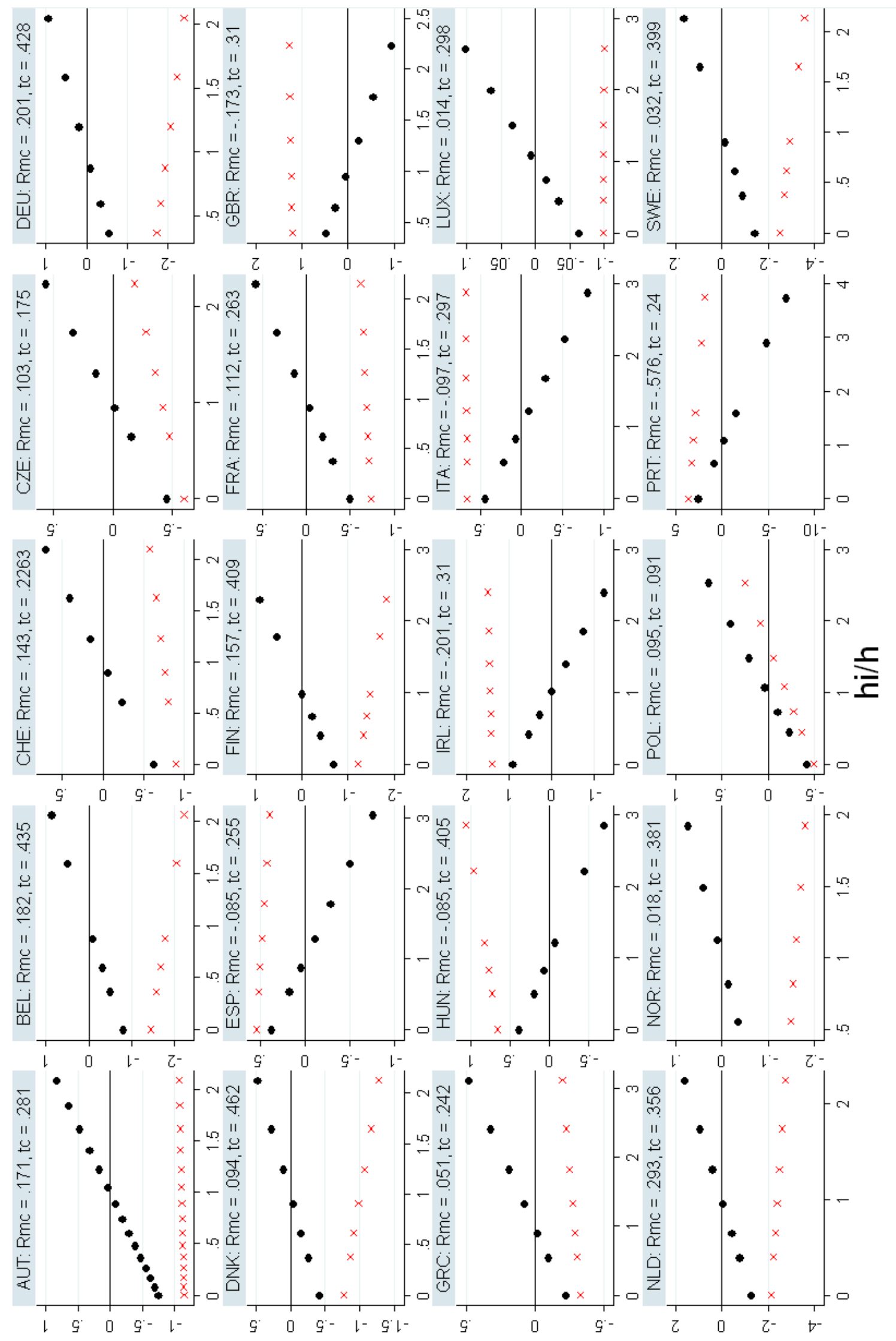

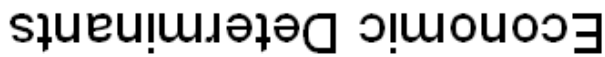


In order to follow the description of the theoretical model which is summarized in figure 3 , we plot these predicted values by the proportional education of the native $\left(h_{i} / h\right)$. Moreover, we plot first the predicted values determined by the labor market mechanism (in black) and then the sum of the predicted values determined by the labor market mechanism and the tax-benefit mechanism (in red). Figure 5 plots the impact of the economic determinants on attitudes regarding immigrants from poor and European countries. The theoretical predictions are fully confirmed. Taking for example Belgium, where immigrants are less educated than the average resident $\left(R_{c}^{m}>0\right)$, the labor market mechanism is harmful to low skilled natives and beneficial for high skilled natives. This can be seen in the positive slope with a negative intercept (black points). From the tax-benefit point of view, less educated immigrants would represent a burden for all natives, reducing the slope according to the level of the taxes $\left(t_{c}\right)$. We expect that the slope changes sign if the marginal tax rate is higher than 29\%, which is indeed the case. For Belgium, the cumulated effect of economic mechanisms is that natives are against immigration, and this negative attitude is stronger for skilled natives. This exercise can be made for all countries giving a detailed panorama of attitudes according to the economic determinants.

Figure 5 provides a clear illustration of the economic factors determining attitudes, but does not clarify the importance of individual values and beliefs. Figure 6 concerns the same group of immigrants (from poor and European countries) and shows the impact of these values and beliefs comparing them to the total prediction. The first observation is that the attitudes are mostly determined by individual values and beliefs; by contrast, the economic determinants seem to play a marginal role. Second, individual values and beliefs are highly correlated to the level of native's education, the more the native is educated, the more positive is his attitude toward immigration. This seems to strongly confirm Hainmueller and Hiscox's (2007) even if economic determinants are very significant 15

\footnotetext{
${ }^{15}$ Another result supporting the thesis of Hainmueller and Hiscox (2007) is the positive and significant coefficient of natives' education in all regressions. Besides, to test their main argument, we proceed to regress the random effect regressions with a dummy variable equals to one if the native has college or university education. The coefficient of this dummy is positive and significant and coefficients of the economic determinants do not change significantly. However, the coefficient of the natives' education is smaller thought still positive and significant. This confirms that the effect of education on positive attitudes, especially for individuals with college or university degree.
} 

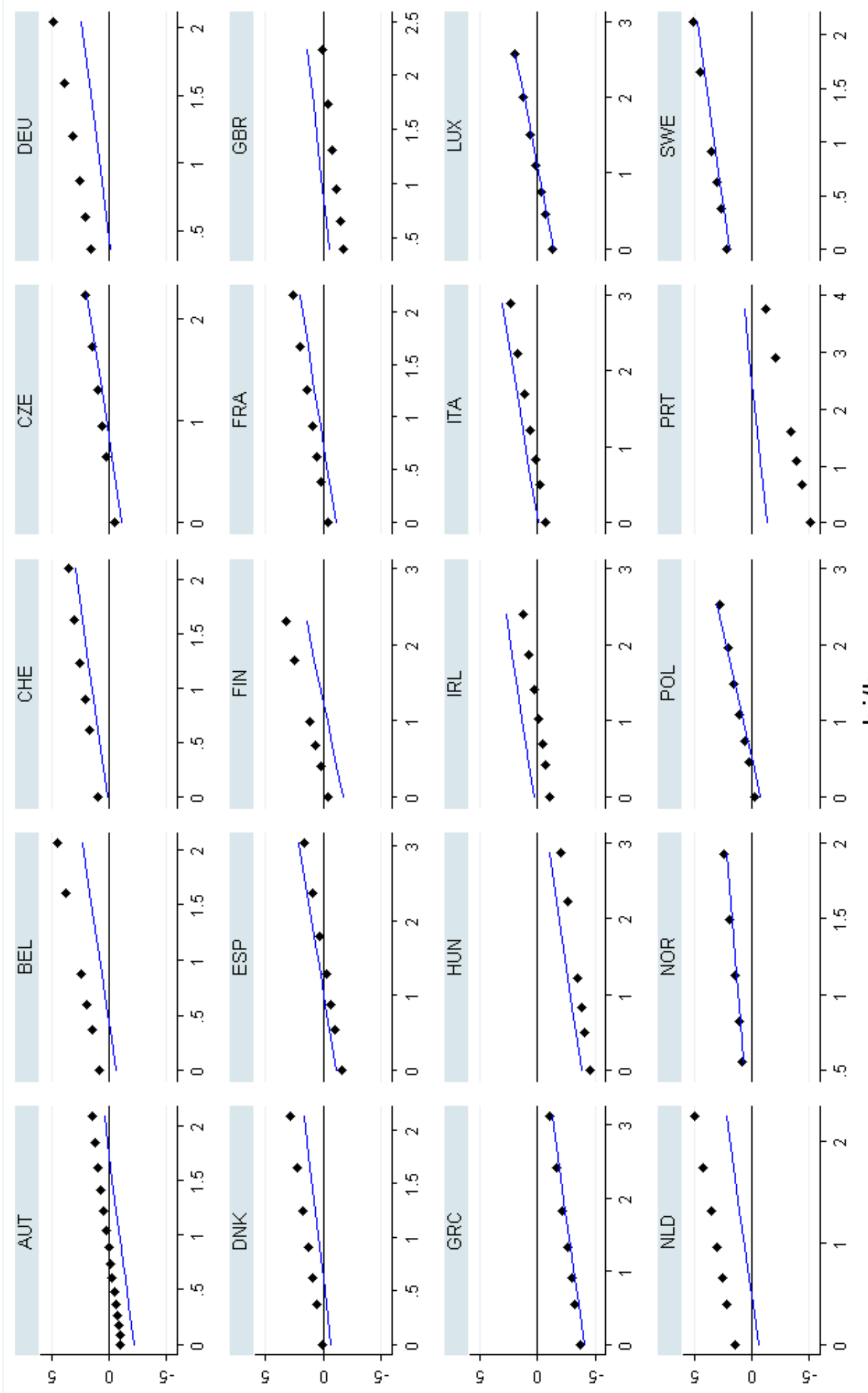
Figures ?? to ?? in Appendix III reproduce this analysis for the other groups of immigrants, respectively for immigrants from rich and European countries, for immigrants from poor non-European countries and for immigrants from rich non-European countries. All theoretical predictions are confirmed for each case, accordingly to the level of the taxes $\left(t_{c}\right)$ and the education level of the immigrant group $\left(R_{c}^{m}\right)$. Also, the individual attitudes present the same shape, being an increasing function of the native's education.

\section{Conclusion}

This paper develops and estimates a structural model to assess the relative impact of the economic and non-economic determinants of attitudes toward immigration. We consider the labor market mechanism, the tax-benefit mechanism and the individual values and beliefs. According to the first mechanism, natives have a positive attitude to immigrants with a complementary level of education. The second mechanism implies that a low skilled immigrant represents a net burden to be supported by all natives in the welfare state. Finally, the third mechanism considers that individuals are more open to diversity and other cultures if they are more educated.

Using data for 20 European countries in 2002, we find a very significant impact of the labor market and the tax-benefit mechanisms on attitudes towards migration. By contrast to previous contributions (Facchini and Mayda, 2009; Hanson et al., 2007), our results are obtained by controlling for unobserved individual beliefs about immigration in general and by using detailed data on immigrants' education levels. Finally, simulations with our structural model indicate that although these two economic mechanisms matter, their net effect is much smaller than the impact of other individual factors on attitudes towards immigration. This result lends some support to Hainmueller and Hiscox's (2007) argument that individual values and beliefs are predominant in the explanation of these attitudes. It can be partly explained by the fact that the two economic mechanisms tend to neutralize each other. (...)

\section{References}

Chamberlain ,G., 1984, "Panel Data," Chapter 22 in Z. Griliches and M. Intrilligator, eds., Handbook of Econometrics, North-Holland, Amsterdam, 1247-1318.

Docquier, F., B. L. Lowell And A. Marfouk, 2009, "A gendered assessment of highly skilled emigration," Population and Development Review, 35 (2), 297-322.

Dustmann, C. And Ian P. Preston, 2007, "Racial and Economic Factors in Attitudes to Immigration," The B.E. Journal of Economic Analysis \& Policy, 7(1): Advances, Article 62.

FACChini, G. AND A. M. MAYDA, 2008, "From individual attitudes towards migrants to migration policy outcomes: Theory and Evidence," Economic Policy, 56: 651 - 713.

Facchini, G. And A. M. MAyda, 2009, "Individual attitudes towards immigrants: Welfare-state determinants across countries," Review of Economics and Statistics 91(2): pp. 295-314.

Greene, W. P., 2003, Econometric Analysis - Fifth Edition, Englewood Cliffs: Prentice Hall.

Hainmueller, J. And M. J. Hiscox, 2007, "Educated Preferences: Explaining Attitudes Toward Immigration in Europe," International Organization, 61, pp. 399-442. 
Hanson, G. And K. Scheve and M. Slaughter, 2007, "Local Public Finance and Individual Preferences over Globalization Strategies," Economics and Politics, 19: 1-33.

Klenow, P., A. Rodriguez-Clare, 2005, "Externalities and Growth," Handbook of Economic Growth, Volume 1A, Aghion, P. and S. N. Durlauf (eds), North-Holland.

Krueger, A. B., 1999, "Measuring Labor's Share," American Economic Review, 89(2), pp. $45-51$.

MAYDA, A. M., 2006, "Who is against immigration? A cross-country investigation of individual attitudes toward immigrants," Review of Economics and Statistics, 88(3), pp. 510-530.

Psacharopoulos, G. And H. A. Patrinos, 2004, "Returns to investment in education: a further update," Education Economics, 12(2), pp. 111-134.

OECD, 2007, "International Migration Statistics ," SourceOECD Vol 2007 release 01.

OECD, 2008a, "A Profile of Immigrant Populations in the 21st Century: Data from OECD Countries," OECD Publications.

O’Rourke, K., R. Sinnott, 2006, "The Determinants of Individual Attitudes Towards Immigration," European Journal of Political Economy, 22 :838-861.

Scheve, K.F., M.J.Slaughter, 2001, "Labor Market Competition And Individual Preferences Over Immigration Policy," Review of Economics and Statistics, 83(1): 133-145.

White, H., 1980, "A Heteroskedasticity-Consistent Covariance Matrix Estimator and a Direct Test for Heteroskedasticity," Econometrica, 48(4): 817-838. 